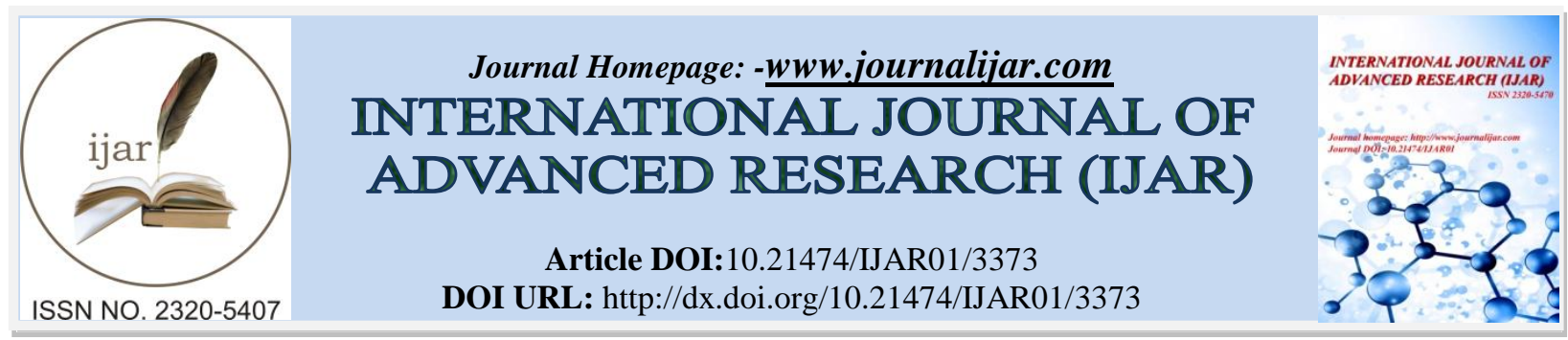

RESEARCH ARTICLE

\title{
ROLE OF INNOVATIVE PEDAGOGICAL TOOLS IN ENHANCEMENT OF THE QUALITY OF ENVIRONMENTAL EDUCATION IN PRIMARY SCHOOLS: AN INDIAN PERSPECTIVE.
}

\author{
Asha Nagendra ${ }^{1}$, Bandana Preet Kaur Jolly ${ }^{2}$, Neha Ahlawat ${ }^{2}$ and Utkarsh Jathar ${ }^{2}$. \\ 1. Professor, Symbiosis International University, Pune. \\ 2. MBA Students, Symbiosis International University, Pune.
}

\section{Manuscript Info}

Manuscript History

Received: 25 December 2016

Final Accepted: 16 January 2017

Published: February 2017

Key words:-

Innovative, Pedagogy, Environmental Sustainability.

\section{Abstract}

It goes without saying that education without experiential exposure is futile. Learning anything is best understood when it is retained for long and this can be ensured only when the knowledge that one has gained can be applied to real life situations. Environmental Education is a course which teaches an individual the basic essence of the living surroundings. Having understood the significance and the implications of doing a course on environmental education, the study undertaken gives an insight into the different pedagogical tools that have been adopted across the three top notch schools in Pune. Emphasis has been laid on such tools because this channel facilitates the flow of knowledge from the learned to the learners. The objective of the study was to analyze the Role of Innovative Pedagogical Tools and Teaching Techniques adopted by primary level schools to evaluate the effectiveness in terms of predefined learning outcomes of environmental education. Primarily, an in depth study of the composition mix of the theory-practical element that exists in the pedagogy used by each of the schools was examined followed by evaluating the success of the respective composition mix. Since the research was extended to more than one school it helped us to give a broad outlook in terms of the innovative modes adopted in the delivery mechanisms. The study helped us to find the highlights; the positives and negatives of the techniques used to impart the subject matter. It also examined the limitations on part of the students, teachers and the parents that hinder the smooth functioning of the teaching-learning process and seeks to give valuable suggestions so that the activity is translated into a more meaningful practice. It was also found that there is a fundamental change in the existent syllabi of environmental education in schools which now promotes cognitive capacity and resourcefulness in order to make the child curious about social phenomena thereby nurturing the curiosity and creativity of the child particularly in relation to the prevalent environmental uncertainties and related sustainability goals. Theresearch intends to help policy makers in formulating an appropriate response strategy with regards to primary level education in India. Finally, the research aimed to develop and implement an effective tool kit for environmental education, based on the identified 
gaps and assessment. The study was however limited to survey results based on research carried out in three schools of Pune.

Copy Right, IJAR, 2017,. All rights reserved.

\section{Introduction:-}

"What sculpture is to a block of marble, environmental education is to the children!" - Joseph Addison:-

The role of education as a facilitator of social and economic progress is well acknowledged universally. Education is the most critical input for endowing people with the requisite skills and knowledge for productive employment opportunities in the future. Thus, continuous enhancements in the methods of education delivery are not only expected to augment efficiency but also amplify the overall quality of life. Education facilitates children to set an objective in life and consecutively enables them to work towards that set goal, exploiting their true potential in the process. This role of education stands uncontested and valid even today.

However, due to immense competition in every sphere and the constant pressure to perform well, the role of education has been reduced to simply being an instrument of material success. Individual ambitions and unreasonable competitive practices are placed above the joy of learning and gaining knowledge from each other.

It needs to be understood that students are not just young people for whom adults should devise solutions. They are critical observers of their own circumstances and needs, and should be participants in discussions and problem solving related to their education and future prospects. Hence, participatory learning and teaching, emotion and experience need to have a definite and valued place in the classroom. The topic of our research paper is "Role of Innovative Pedagogical Tools in Enhancement of the Quality of Environmental Education in Primary Schools: An Indian Perspective".

The prime motive behind selecting environmental education was due to the fact that only this course had the leverage of including innovative techniques to a considerable extent. In addition, it was also imperative to question whether or not environmental education at the elementary level ensures that the future population is more concerned and aware about the environment and issues related to it.

\section{Objectives:-}

1. To analyze the scope and significance of Environmental Education being imparted in Indian schools as part of the Primary Level Education in India.

2. To determine the relationship between the use of innovative pedagogical tools and enhancement in the quality of education at primary level in schools.

\section{Limitations:-}

1. The study was limited to three schools in the city of Pune.

2. The study was limited to the subject of Environmental Education.

\section{Review of Literature:-}

Gupte, Medha (2015) in her paper titled "Does information and communication technology (ICT) have an important role to play in Indian higher education?", has researched about how ICT can play a crucial role in transforming the current education scenario in India from the point of view of three critical stakeholders: teachers, students and government. She further explains that if used creatively, CT will not only make a big difference in the current teaching-learning methodologies practiced in Indian schools but also help in the incorporation of $21^{\text {st }}$ century skills like digital literacy, innovative thinking, creativity, sound reasoning and effective communication. The study attempts to give a comprehensive outlook on how ICT is likely to enhance the quality of education through blended learning, by augmenting the traditional chalk and talk method.

NCERT (2005), in its review of the National Curriculum Framework, specifically pointed out that it is imperative that learning at school be seen beyond the use of textbooks and greater emphasis be laid on experiential learning while imparting knowledge. The document suggested to adopt a comprehensive strategy which would ensure learning without any kind of burden on the students. 
Further, the report recommended the need for a fundamental change in the existent syllabi of environmental education in schools so as to promote cognitive capacity and resourcefulness in order to make the child curious about social phenomena, starting with the family and moving on to wider spaces and to finally nurture the curiosity and creativity of the child particularly in relation to the prevalent environmental uncertainties prevailing in the world.

\section{Research Methodology:-}

Sampling Method used and Size of Sampling:-

Sampling Technique:-

Probability Sampling Technique was used to carry out the research. Under this, the following technique of sampling was used:

Stratified Random Sampling - The first step entailed identifying a particular cluster (area) to narrow down the population size. For this, the case perspective of Pune was taken into consideration and the observations were assumed to be representative of the situation pan India. Further, within Pune as well in order to create stratified random samples, three schools were identified to carry out the primary spade work. Additionally, to form even smaller groups/strata from within these schools, teachers were characterized based on their designation. Finally, the stratum which was chosen for the study was that of the PRT (Primary Teacher) teachers responsible for Environmental Education in their respective schools.

\section{Sample Size:-}

A field visit was undertaken across three renowned schools in Pune. The sample size comprised of fifty respondents comprising of School Teachers (TGT, PRT, PGT) i.e., approximately seventeen per school.

\section{Data Collection:-}

\section{Primary Data}

Primary data collection was the principal mode of enquiry. It involved collecting data through a questionnaire consisting of twenty questions which essentially aimed at bringing out relevant data to meet the objectives of the research.

\section{Secondary Data:-}

The critical data sources included; Environment Education (EE) curriculum in Schools, Recommendation by NCF (National Curriculum Framework) 2005, Various Publications targeted at enhancing environmental education such as that of Eklavya, National Council of Educational Research and Training (NCERT), and Centre for Environment Education (CEE), Other Books available in the market, alternate books/ games/ audio- visual exposure given by schools if any.

Other Sources of secondary data collection encompassed; journals and previously published papers available over the internet.

\section{Data Analysis:-}

Once the relevant data had been gathered, the researchers undertook both qualitative as well as quantitative analysis of the same.

\section{Qualitative Analysis:-}

As part of the qualitative study, an experimental design was structured, which entailed conducting a brief classroom session in each of the three schools. Such kind of analysis is condensed under the umbrella of 'Observations through being Participant in Education Delivery' methodology.

\section{Quantitative Analysis:-}

On the other hand, the survey results were used to scientifically and objectively classify the data using certain commonly used tools such as SPSS,Microsoft Excel and Microsoft Power Point. Relevant excel formulas, charts and graphs were then used to further infer and test the applicability of the existing hypothesis. 


\section{Hypothesis:-}

$>$ Ho (Null Hypothesis): Innovative means of teaching does not have any role to play in enhancing the quality of education being imparted at various levels.

$>$ H1 (Alternate Hypothesis): Innovative pedagogical tools augment the overall understanding of a student and there is a definite behavioral change which can be observed in the student as a result of the same.

\section{Results:-}

Figure 1:- Level of Agreement on appropriateness of curriculum in achieving prescribed environmental education goals

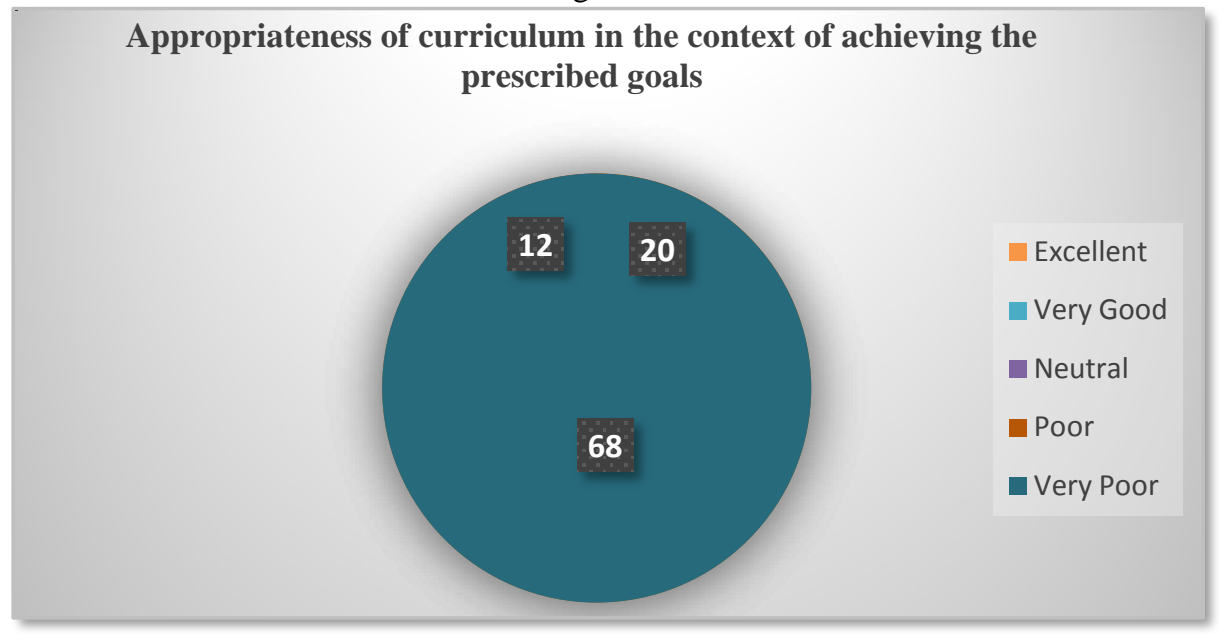

\section{Discussion:-}

From the above Figure 1, it is seen that $68 \%$ of the respondents agreed that the curriculum was appropriate enough to achieve the prescribed environmental education goals at Primary level in schools. The respondents opined that present syllabus is designed to forge an integrated perspective for the primary stage of schooling that draws upon insights from Sciences, Social Studies and Environmental Education.

Table 1:- Level of Agreement pertaining to long term objectives being targeted by the proposed curriculum.

\begin{tabular}{|l|l|l|l|}
\hline SNo & $\begin{array}{l}\text { The Curriculum Targets to Achieve Certain Long Term Objectives (Behavioural } \\
\text { Change/Awareness/Social Benefit) }\end{array}$ & $\mathbf{n = 5 0}$ & Percentage \\
\hline a) & Strongly Agree & 14 & 28 \\
\hline b) & Agree & 22 & 44 \\
\hline c) & Neutral & 8 & 16 \\
\hline d) & Disagree & 4 & 8 \\
\hline e) & Strongly Disagree & 2 & 4 \\
\hline
\end{tabular}

\section{Discussion:-}

From the above Table 1, it is evident that most of the respondents firmly believed that the proposed curriculum definitely contributes towards inculcating a behavioral change amongst students in regards to developing sensitivity towards the environment.

Figure 2: Level of Agreement on the statement that students learn faster with innovative techniques like games, quiz, presentations and illustrations are used 


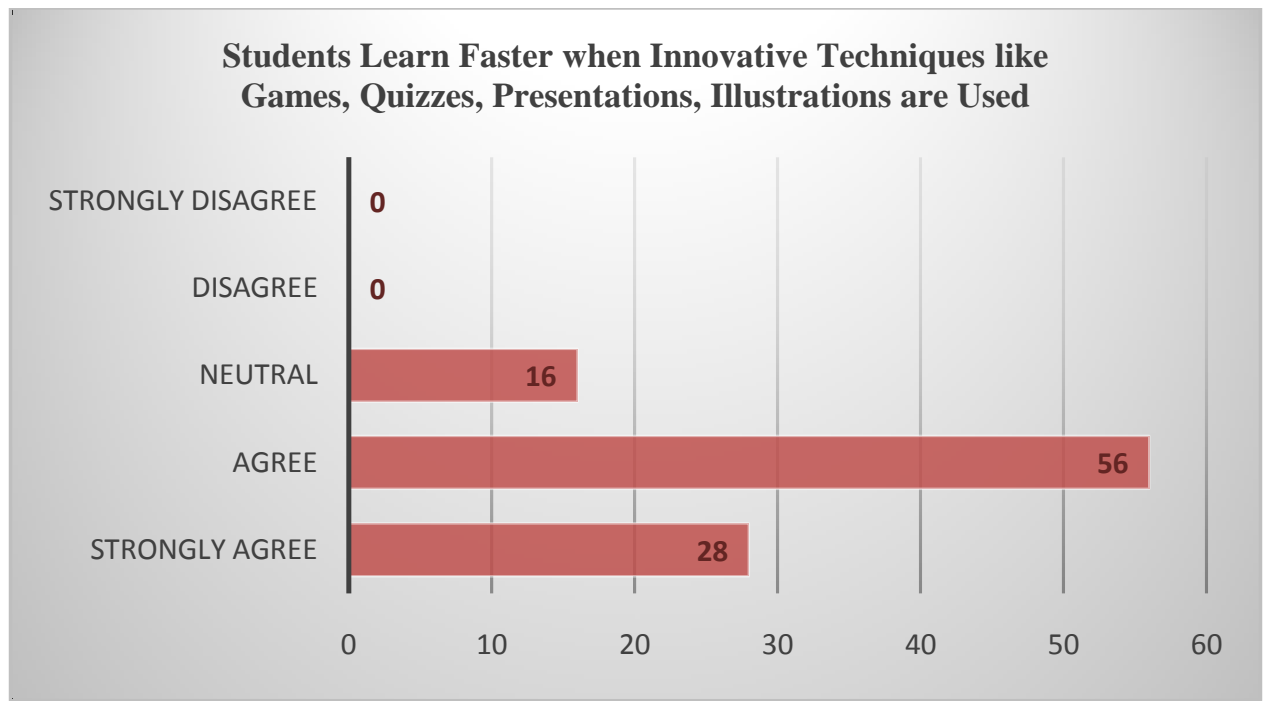

\section{Discussion:-}

From the above Figure 2, it can be seen that $56 \%$ of the teachers agreed with the notion that innovative methodologies have a definite positive role to play towards imparting quality education and ensuring faster learning amongst the students. Further, they also believed that, text books should only be used as guidelines in terms of what topics need to be covered. The prime focus should be on alternative teaching techniques. Learning by rote is must in terms of enhancing reading and writing skills but for experiential learning it is imperative that innovative methods be used.

Figure 3: Level of Agreement that the students tend to be more participative when innovative teaching means are used rather than conventional teaching methods

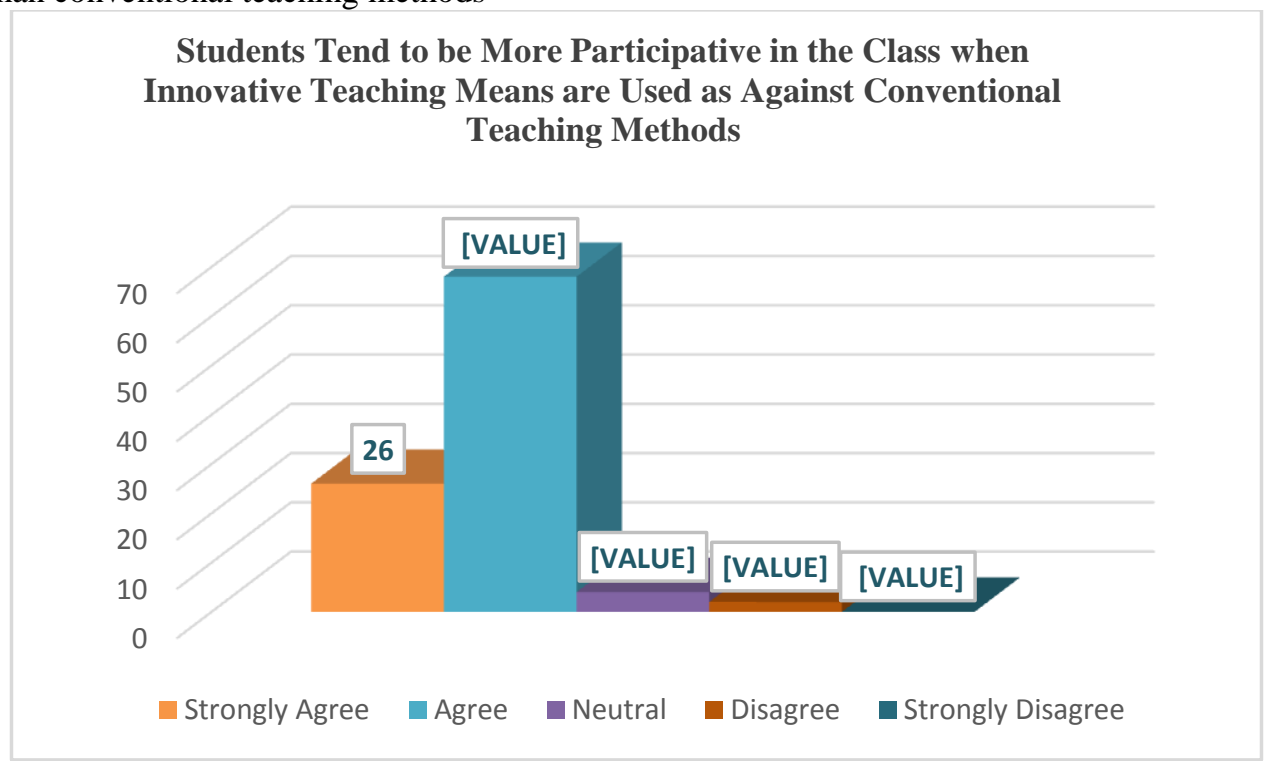

\section{Discussion:-}

From the above Figure 3, it can be seen that $68 \%$ of teachers agree that students tend to be more participative and enthusiastic in class when innovative teaching means are used as against conventional teaching methods. They further opined that since it is a life subject, rather than gaining theoretical knowledge only, understanding of the concepts through practical experience is more important. An interesting initiative which was highlighted includes - a No-Vehicle Day on a weekly basis to reduce the pollution level. 
Further, they also believed that if the curriculum is focused on learning by doing approach then the students tend be more enthusiastic, active and participative in the class.

Figure 4:- Level of Agreement on the fact that conducting relevant workshops on Environmental related issues tend to enhance the cognitive ability of students

\section{Conducting Relevant Workshops Impacts the Cognitive Ability of} Students and Sensitizes them towards their Immediate Environment

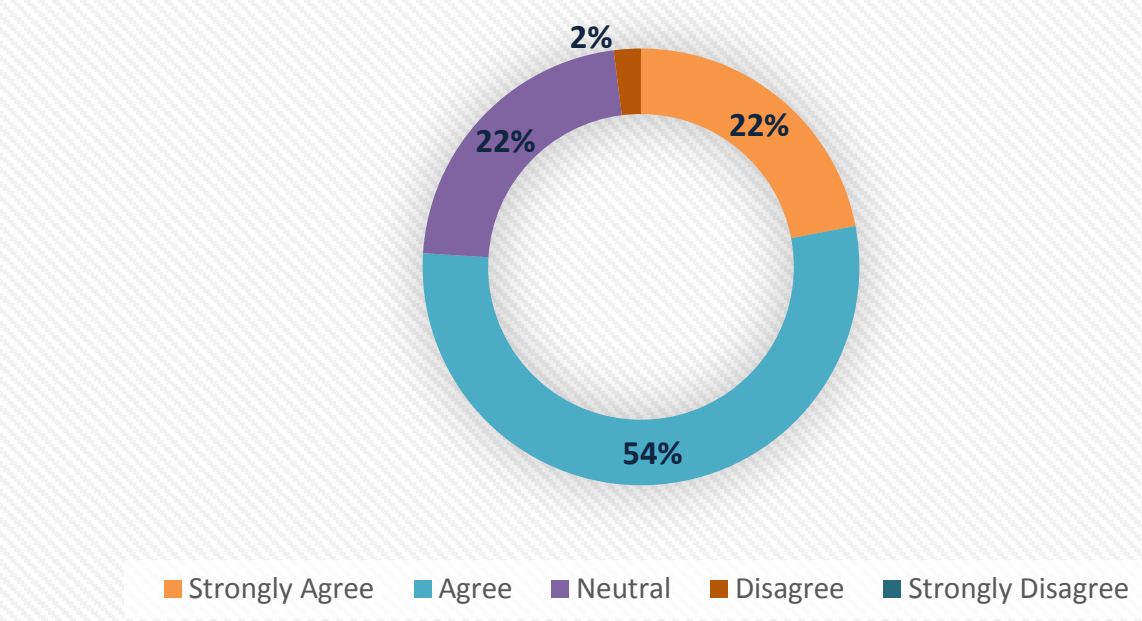

\section{Discussion:-}

From the above Figure 4, it can be inferred that more than $50 \%$ of the respondents agreed to the fact that conducting relevant workshops on current Environmental related issues tend to nurture the curiosity and creativity of the child particularly in relation to the natural environment. Teachers also felt that these workshops engage the child in exploratory and hands-on activities and helps them acquire basic cognitive and psychometric skills through relevant observation, classification and inference.

\section{Hypothesis Testing:-}

In order to establish a quantitative relationship between Innovative Techniques adopted and Performance of the Students in Environmental Education subject, two variables namely Quantitative Performance Technique (QPI) and the Number of Sessions conducted using Innovative Teaching Methodologies were studied.

Mathematically; QPI = Grand Total Marks of Students Appeared / (Total Number of Students * Number of Subjects)

A Correlation (Bivariate) analysis was done using SPSS. A Two-tailed test (which allows positive or negative correlation) was done to calculate Karl Pearson's Correlation Coefficient.

Note - For this particular test, the subject wise marks of Class IV students from all the three schools, were collected and studied.

Table 2:- Calculation of $\mathrm{p}$ value.

\begin{tabular}{|l|l|l|l|}
\hline \multicolumn{2}{|c|}{} & QPI & Number of Innovative Sessions \\
\hline \multirow{4}{*}{ QPI } & Pearson Correlation & 1 & 0.760 \\
\cline { 2 - 4 } & Sig (2-tailed) & & 0.001 \\
\cline { 2 - 4 } & $\mathrm{N}$ & 20 & 20 \\
\hline \multirow{2}{*}{\begin{tabular}{l} 
Number $\begin{array}{l}\text { Innovative } \\
\text { Sessions }\end{array}$ \\
\cline { 2 - 4 }
\end{tabular}} & Pearson Correlation & 0.760 & 1 \\
\cline { 2 - 4 } & Sig (2-tailed) & 0.001 & \\
\cline { 2 - 4 } & $\mathrm{N}$ & 20 & 20 \\
\hline
\end{tabular}

*Correlation is significant at the 0.01 level (2-tailed). 
Since, the $\mathrm{p}$ value is $<=0.05$ (significance level), the test is significant (there is a significant relationship between the number of sessions held using Innovative Techniques and the QPI).

Also, the value 0.760 indicates a strong positive Pearson correlation between the two variables, that is, $r(18)=$ $0.760, \mathbf{p}=\mathbf{0 . 0 0 1}$.

The above resultrejectsthe null hypothesis which states that "Innovative means of teaching does not have any role to play in enhancing the quality of education being imparted at various levels".

Hence, the alternate hypothesis which states that "Innovative pedagogical tools augment the overall understanding of a student and there is a definite behavioral change which can be observed in the student as a result of the same" can be accepted.

\section{Conclusion:-}

The conclusion of the entire study are being discussed in the light of the objectives.

The first objective of the study was to "analyze the scope and significance of Environmental Education being imparted in Indian schools as part of the Primary Level Education in India".

It was found that increasing concern on Environmental Education (EE) in India gained impetus after its importance was recognized by the Government and requisite policies were framed subsequently to introduce Environmental Education in schools. After execution of the planned study, one of the key findings was that there was a difference in the learning outcomes across the three schools. In case of the first school under study, it was observed that the curriculum focused more on learning by doing approach. In line with the stated objectives of the curriculum it was felt that the students were more enthusiastic, active, participative and willing to learn. Further, it was analyzed that they were able to apply the knowledge in a better way when resorted to innovative means. On the contrary, in the other two schools, students were seen to be more mechanistic in their response as the school authorities preferred text book based learning. The restrictive exposure given to the students lead to a limited applicability of their knowledge in real life situations which further narrowed down their scope of thinking. Another interesting result which can be inferred is that particularly in case of government aided schools due to lack of in service programmes/training of the teachers their ability to implement the prescribed curriculum effectively in the class, has been restricted. On the other hand, due to continuous training of the teachers in the other schools they have been able to enhance the quality of education delivery.

The second objective of the study was to "determine the relationship between the use of innovative pedagogical tools and enhancement in the quality of education at primary level in schools".

There was a definite positive connection which could be established between the use of innovative pedagogical tools and enhancement in environmental education at the primary level. Certain positive initiatives were taken by the schools like Cleanliness Drives (Kirloskar Clean School Green School Programme), Participation in the Green Olympiad at the National Level which encouraged students to develop knowledge about the global environment situation.

Although the schools have adopted the E-learning method of education yet there is ample scope for augmenting the effectiveness of the delivery mechanisms. Since the study involved a very broad base of students, one of the core issues which came to light was the existence of a language barrier. During certain instances this was an evident obstacle towards imparting vital knowledge. So, in order to overcome this problem, the teachers have to ensure that at all times certain parity exists while conducting classes.

It was also observed that in majority of the classes since the strength of the students is high it leads to two pertinent problems- firstly, the grasping power of all the students is not similar as a result of which special attention needs to be given to certain students. Secondly, the attention span of the students varies and thus they tend to get distracted easily. An implication of this is that only some of them actually benefit from the classes. Another appalling gap which continues to persist in the whole system is the trivial role played by the parents due to lack of adequate education and awareness. There is a discontinuity in the learning process which is carried from the classroom to their respective homes. Finally, we could say that since the level, scale and form of implementation of the teaching methods varies in different schools, there is ample scope for further research in the same domain by considering a wider spectrum. 


\section{Recommendations:-}

A comprehensive outlook emerged post the intensive research. In lieu of the Participant-Observant Method, critical stakeholders were identified and it was observed that each one of them had an imperative role to play. The prominent links which arose out of the study include:

Weakest Link - Parents:-

Policy Level: The policy design is highly desk bound and the policy makers fail to take into consideration the viability of the same. It needs to be realized that the learning process is not confined to the schools only. Therefore, more focus should be laid on After School Centers so that continuity in the learning process is maintained. It is thus imperative that the whole system is streamlined and is more cost effective so that it does not automatically exclude the people who cannot afford it.

\section{Strongest Link - Teachers:-}

Policy Level: At the policy level, work needs to be done towards capacity building of the teachers. The teachers need to be adequately trained on a regular basis by improvising on the Teacher Training Packages.

\section{Critical Link - Pedagogy:-}

Policy Level: In order to ensure experiential learning in the schools certain subsidy mechanism should be put in place. This will ensure that the schools especially the government aided schools have adequate funds available for implementing the requisite tools. Also, a uniform content needs to be developed, taking usage of pedagogical tools into account, in order to maintain an overall parity level across all the schools.

\section{References:-}

1. Aggarwal, J. C. (2009). Landmarks in the history of Modern Indian Education, 6E. Vikas Publishing House Pvt Ltd.

2. Barrett, M. J. (2008). Participatory pedagogy in environmental education: Reproduction or disruption? (pp. 212224). Springer Netherlands.

3. Battiste, M. (2002). Indigenous knowledge and pedagogy in First Nations education: A literature review with recommendations. Ottawa: Apamuwek Institute.

4. Blum, N. (2009). Small NGO schools in India: implications for access and innovation. Compare, 39(2), 235248.

5. Cheney, G. R., Ruzzi, B. B., \& Muralidharan, K. (2005). A profile of the Indian education system. Prepared for the New Commission on the Skills of the American Workforce.

6. Friedman, R. S., \& Deek, F. P. (2003). Innovation and education in the digital age: reconciling the roles of pedagogy, technology, and the business of learning. Engineering Management, IEEE Transactions on, 50(4), 403-412.

7. Gupte, M. (2015). Does Information And Communication Technology Have An Important Role To Play In Indian Higher Education? Abhinav-International Monthly Refereed Journal of Research in Management \& Technology (Online ISSN 2320-0073), 4(1), 41-46.

8. Kumar, K. (1993). Literacy and primary education in India. Knowledge, culture and power: International perspectives on literacy as policy and practice, 102-113

9. Lockheed, M. (2012). The condition of primary education in developing countries. Effective schools in developing countries, 20-40.

10. NCERT. (2005). National Curriculum Framework.

11. Sonowal, C.J. (2009). Environmental Education in Schools: The Indian Scenario. Journal of Human Ecology, 28(1): 15-36.

12. Retrieved fromhttp://www.unesco.org/new/en/education/themes/leading-the-international-agenda/educationfor-all/the-efa-movement/on 08/07/2015.

13. Retrieved fromhttp://ssa.nic.in/ on 09/07/2015.

14. Retrieved fromhttp://www.unesco.org/new/en/education/themes/leading-the-international-agenda/educationfor-all/on 10/07/2015. 